\title{
Glutamine supplementation in a child with inherited GS deficiency improves the clinical status and partially corrects the peripheral and central amino acid imbalance
}

\author{
Johannes Häberle ${ }^{1 *}$, Noora Shahbeck ${ }^{2}$, Khalid Ibrahim³ ${ }^{3}$ Bernhard Schmitt ${ }^{4}$ Ianina Scheer ${ }^{5}$, Ruth O'Gorman ${ }^{6}$,
} Farrukh A Chaudhry ${ }^{7 \dagger}$ and Tawfeg Ben-Omran ${ }^{2,8,9+}$

\begin{abstract}
Glutamine synthetase (GS) is ubiquitously expressed in mammalian organisms and is a key enzyme in nitrogen metabolism. It is the only known enzyme capable of synthesising glutamine, an amino acid with many critical roles in the human organism. A defect in GLUL, encoding for GS, leads to congenital systemic glutamine deficiency and has been described in three patients with epileptic encephalopathy. There is no established treatment for this condition. Here, we describe a therapeutic trial consisting of enteral and parenteral glutamine supplementation in a four year old patient with GS deficiency. The patient received increasing doses of glutamine up to $1020 \mathrm{mg} / \mathrm{kg} /$ day. The effect of this glutamine supplementation was monitored clinically, biochemically, and by studies of the electroencephalogram (EEG) as well as by brain magnetic resonance imaging and spectroscopy.

Treatment was well tolerated and clinical monitoring showed improved alertness. Concentrations of plasma glutamine normalized while levels in cerebrospinal fluid increased but remained below the lower reference range. The EEG showed clear improvement and spectroscopy revealed increasing concentrations of glutamine and glutamate in brain tissue. Concomitantly, there was no worsening of pre-existing chronic hyperammonemia. In conclusion, supplementation of glutamine is a safe therapeutic option for inherited GS deficiency since it corrects the peripheral biochemical phenotype and partially also improves the central biochemical phenotype. There was some clinical improvement but the patient had a long standing severe encephalopathy. Earlier supplementation with glutamine might have prevented some of the neuronal damage.
\end{abstract}

Keywords: Glutamine supplementation, Glutamine synthetase, Chronic encephalopathy, Neonatal onset seizures, Hyperammonemia, Qatar consanguinity, Therapeutic trial, GABA, Neurotransmitter replenishment, SLC38

\section{Introduction}

Glutamine synthetase (GS) is a ubiquitously expressed cytosolic key enzyme of nitrogen metabolism [1,2]. In an ATP-dependent manner, GS catalyzes the synthesis of glutamine from glutamate and ammonia and is a source for the entire body glutamine pool, since there is no net absorption of glutamine from the intestine in healthy individuals $[3,4]$. The synthesis of glutamine from GS is

\footnotetext{
* Correspondence: Johannes.Haeberle@kispi.uzh.ch

${ }^{\dagger}$ Equal contributors

'Division of Metabolism and Children's Research Center, University Children's Hospital Zurich, 8032 Zurich, Switzerland

Full list of author information is available at the end of the article
}

the only known reaction for endogenous glutamine production in mammals, and GS also plays an important role in many metabolic pathways e.g. by balancing the nitrogen pool between different compartments, by detoxifying ammonia and glutamate in brain astroglial cells $[5,6]$ or by providing osmotic cell homeostasis [6-8]. GS is expressed in utero in early human fetuses [9] and is a prerequisite for early development in mice and drosophila $[10,11]$. The product of the GS reaction, glutamine, is the major amino moiety donor for other amino acids, glucose precursors, purines and pyrimidines, and adenosinemonophosphate [12] and is the central metabolite for the temporary storage and transport of nitrogen between

\section{() Biomed Central}


different organs [1]. Glutamine has a functional impact on many metabolic processes in peripheral organs, such as $\mathrm{pH}$ homeostasis in the kidney and regulation of plasma glucose levels in the pancreas $[13,14]$. In the central nervous system, glutamine is considered to be the primary precursor of the neurotransmitter amino acids glutamate and $\gamma$-aminobutyric acid (GABA), the most abundant fast excitatory and inhibitory neurotransmitters, respectively [15-17].

The pivotal roles of glutamine underline the importance of a functional GS for normal human physiology, so it is not surprising that patients with an inherited defect of GS demonstrate a severe clinical phenotype. These patients either died from neonatal multi-organ failure $[18,19]$ or, as in the case of the patient described in this study, survived albeit suffering from severe epileptic encephalopathy [20]. Unfortunately, there is no established treatment for GS deficiency but supplementation of the missing amino acid would be a first-thought rationale. Glutamine supplementation has already been tested in healthy volunteers and doses up to $750 \mathrm{mg} / \mathrm{kg} / \mathrm{d}$ have proved to be safe during short-term application [3,21-24]. However, since chronic hyperammonemia may be a consequence of GS deficiency [20], supplying glutamine to a patient with GS deficiency could augment ammonia levels, potentially causing additional toxicity [25]. Therefore, unlike therapy in the other amino acid biosynthesis disorders [26,27], glutamine supplementation must be carefully considered in the light of the potentially damaging effects of hyperammonemia. A careful therapeutic trial with thorough monitoring was necessary in order to establish the safety of glutamine supplementation.

In the current study, we present a clinical trial in the only known living GS deficient patient with severe neurological sequelae. We demonstrate that regulated glutamine supplementation with careful monitoring enables correction of the biochemical defect and provides some improvement in the neurological status of the patient.

\section{Methods}

\section{Patient - clinical situation}

The natural course of the patient has been described previously [20]. In brief, he was born to first cousin parents from Sudan after an uneventful pregnancy. At birth, he did not need resuscitation, but soon he was noted to have generalized hypotonia, lower limb hyperreflexia, cloni and episodes of eye staring lasting for 2-3 minutes. Generalized tonic-clonic convulsions started at 13 days and, despite extended anticonvulsant therapy, epileptic seizures persisted, contributing to a severe developmental delay. In addition, the patient demonstrated one episode of necrolytic erythema at 38 months [20] when serum glutamine levels were $<10 \mu \mathrm{mol} / \mathrm{L}$.
At the start of the therapeutic trial, the patient was in a stuporous state with only a few episodes of apparent alertness during the day that each lasted about 15 minutes. If awake, the parents were able to identify emotional expressions such as satisfaction, hunger or anger. He was mainly fed via his gastrostomy tube but was also able to suck small amounts of his diet. Convulsions were noted every day, but it was unclear whether all should be classified as epileptic seizures. Overall, the patient had a robust constitution and a clinically intact immune system.

Before the start of the therapeutic trial, detailed clinical and nutritional assessments and biochemical investigations were performed at Hamad Medical Corporation, Doha-Qatar. In an attempt to lower plasma ammonia as much as possible before the initiation of the glutamine therapy, the patient received increasing doses of lactulose and neomycin to limit ammonia uptake from the gut. This was done under close monitoring for dehydration and electrolyte imbalances and resulted in a shortterm decrease of plasma ammonia to $38 \mu \mathrm{mol} / \mathrm{L}$. However, as diarrhoea became troublesome, this treatment was no longer tolerated and had to be stopped. The patient was then hospitalized for four weeks ensuring close clinical, laboratory and technical monitoring. The parents of the patient consented to the therapeutic trial which was performed at the University Children's Hospital Zurich. The study was approved by the responsible institutional review board (Kantonale Ethikkommission).

\section{Biochemical investigations at baseline and during monitoring}

Before glutamine supplementation was initiated, baseline metabolic and endocrinologic investigations were done in blood (including fasting plasma amino acid profile, ammonia, growth hormone, thyroid function, vitamins A, E, D and B12, and essential fatty acids) and in cerebrospinal fluid (CSF) (including amino acid profile, free and total GABA, neurotransmitter metabolites, folates, pterines, creatine, guanidinoacetate), in addition to routine biochemical parameters (such as blood count, serum electrolytes, creatinine, ASAT, and ALAT). Amino acid analysis in plasma and CSF was done applying the classical method based on ion exchange chromatography with post column derivatization with ninhydrin using the Biochrom 30+ analyzer (Biochrom, Cambridge, UK). Most metabolic parameters (including tests in CSF) were done weekly, but fasting plasma ammonia and amino acid profiles were obtained daily.

\section{Technical investigations at baseline and during monitoring}

EEG examinations were recorded both in the awake and sleeping state at baseline and at weekly intervals during trial monitoring. 
Cerebral magnetic resonance imaging (MRI) and spectroscopy (MRS) studies were performed with a $3 \mathrm{~T}$ GE HD.xt MRI scanner (GE Healthcare, Waukesha, WI, USA). The imaging protocol included one axial T1 weighted sequence (repetition time $\mathrm{TR}=620 \mathrm{~ms}$; echo time $\mathrm{TE}=21 \mathrm{~ms}), \mathrm{T} 2$ weighted sequences in 3 planes $(\mathrm{TR}=9300 \mathrm{~ms} ; \mathrm{TE}=96 \mathrm{~ms})$, FLAIR $\quad(\mathrm{TR}=9300 \mathrm{~ms}$; $\mathrm{TE}=124 \mathrm{~ms}$; inversion time $\mathrm{TI}=2250 \mathrm{~ms}$ ), diffusion weighted images DWI (35 gradient directions and b_value $=700 \mathrm{~s} / \mathrm{mm}^{2}$, voxel $=0.8 \times 0.8 \times 2.5 \mathrm{~mm}^{3}$ ) and a T1 weighted sequence after intravenous Gadolinium injection.

Single voxel $\left[{ }^{1} \mathrm{H}\right] \mathrm{MRS}$ spectra were acquired from a voxel of interest in the left basal ganglia $\left(15 \times 15 \times 15 \mathrm{~mm}^{3}\right)$, using a point-resolved spectroscopy (PRESS) sequence with repetition time $(\mathrm{TR})=3000 \mathrm{~ms}$ and echo time $(\mathrm{TE})=35 \mathrm{~ms}$. In order to examine the cerebral concentrations of GABA, glutamate, and glutamine in more detail, additional edited spectra were acquired from a $25 \times 40 \times 25 \mathrm{~mm}^{3}$ voxel of interest (VOI) in the left basal ganglia using a MEGA-PRESS sequence [28] with $\mathrm{TR}=1800 \mathrm{~ms}, \mathrm{TE}=68 \mathrm{~ms}$. For each metabolite spectrum, 16 water reference lines were also acquired as part of the standard PROBE acquisition. Metabolite concentrations were derived with LCModel version 6.1-4 F [29], using the unsuppressed water signal as an internal calibration standard. Following this method, the spectrum was modeled as a linear combination of basis spectra from in vitro metabolite solutions of known concentration, (see reference [29] for further details). Since this method incorporates the full multiplet peak profiles for glutamate and glutamine, the relative contributions from these neurotransmitters can be resolved despite their overlapping peaks. Brain MRI and MRS studies were repeated after 2 and 4 weeks, respectively. For comparison, the same MRS protocol was applied in three agematched comparison subjects, referred for MRI for skull malformation, developmental delay, and epilepsy, respectively, with normal cerebral MR imaging.

\section{Glutamine supplementation}

L-glutamine was provided as a powder (Resource ${ }^{\circledR}$ Glutamin, Nestlé Nutrition, Vevey, Switzerland). A low starting regime of $17 \mathrm{mg} / \mathrm{kg} / \mathrm{d}$ divided in eight dosages was chosen because of concerns about the possible toxicity of raising ammonia and glutamate levels. Glutamine was then increased step-wise each day to a final dose of $1020 \mathrm{mg} / \mathrm{kg} /$ on day 21 of the trial. Since fasting glutamine levels did not increase during the first two weeks of the trial, the interval between single dosages was shortened to two hours (Figure 1). To facilitate the treatment, $330 \mathrm{mg} / \mathrm{kg}$ glutamine was administered from 12 p.m. until 8 a.m. as a continuous enteral infusion via the gastrostomy tube after dilution in $100 \mathrm{ml}$ water. Prior to this infusion, the stability of the glutamine solution was confirmed by measurement of glutamine at 0,6 and 9 hours, which yielded steady concentrations (data not shown). To provide information on the parenteral dose of glutamine needed for maintaining normalized plasma glutamine levels, L-glutamine (Dipeptiven ${ }^{\circledR}$, Fresenius Kabi, Stans, Switzerland) was given as a continuous infusion over six hours at a rate of 21 and $31 \mathrm{mg} / \mathrm{kg} / \mathrm{h}$, respectively, and over eight hours at a rate of $41 \mathrm{mg} / \mathrm{kg} / \mathrm{h}$ while enteral glutamine supplementation was paused.

\section{Results}

\section{Clinical situation}

The therapeutic trial lasted for four weeks. On one occasion the patient suffered from a catheter-associated infection requiring targeted intravenous antibiotics (amoxicillin clavulanate, gentamicin). However, the patient remained clinically stable throughout this four week period.

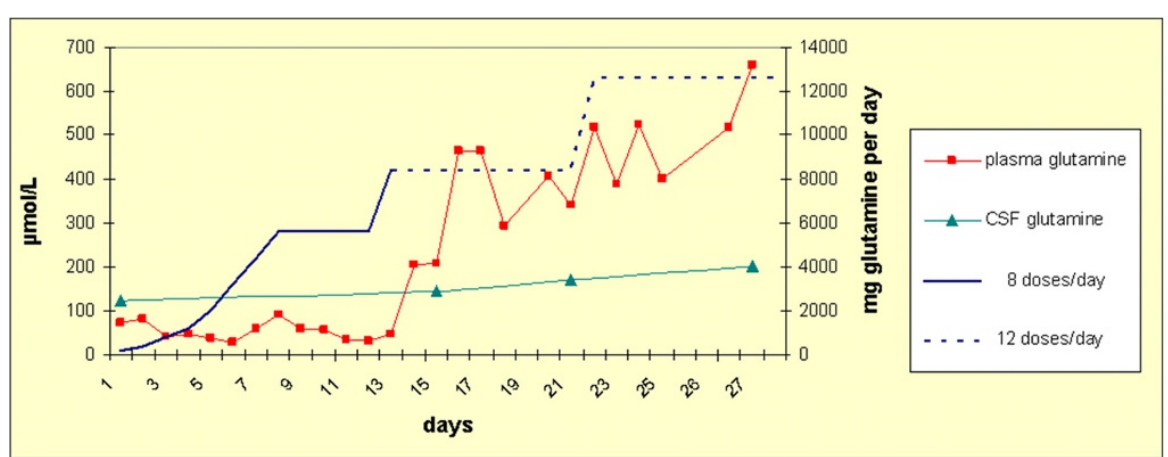

Figure 1 Glutamine dosing regimen and plasma concentrations during the $\mathbf{4}$ weeks trial. Glutamine was initially given 8 doses per day (blue line) but switched to 12 doses per day (blue dotted line) after 14 days treatment. Fasting plasma glutamine concentrations are given (with red -) as obtained every morning and for CSF glutamine concentrations (with turquoise ) illustrating the increase in plasma and CSF glutamine concentrations, respectively, under glutamine supplementation. 
Two weeks after the start of glutamine supplementation, the plasma glutamine concentrations increased with a concomitant improvement in the patient's alertness. This increased alertness was noted by the parents but also by staff members based on prolonged awake phases. In addition, the intensity of smiling of the patient improved resulting in his "longest ever smile" on the last day of the trial as described by the father.

Both enteral and parenteral L-glutamine supplementation was tolerated during the four week trial without side effects. However, when the patient returned to his home country, the parents noticed an increased irritability. Since this was attributed to L-glutamine supplementation, the dose of glutamine was reduced again, however, without accurate documentation.

\section{Monitoring of biochemical parameters}

Considerable concern was focused on the levels of ammonia and glutamate, which remained stable in blood as well as in CSF (Table 1). Fasting concentrations of plasma glutamine were $74 \mu \mathrm{mol} / \mathrm{L}$ (reference range 457-857) at the start of the trial, remaining stable while glutamine was given every three hours, but increasing above the lower limit of normal when glutamine was given at a dose of $700 \mathrm{mg} / \mathrm{kg} / \mathrm{d}$ at a two hourly interval (Figure 1). There was no clear decrease of plasma glutamine related to the catheter-associated infection, but this might have escaped our only once-daily monitoring. Levels of CSF glutamine constantly increased from 121 at baseline to 146, 171 and $201 \mu \mathrm{mol} / \mathrm{L}$ (reference range 333-658) after 2, 3, and 4 weeks of treatment, respectively, but remained below the lower limit of normal in this limited trial period (Table 1 and Figure 1).

Concentrations of creatine and guanidinoacetate in CSF were normal in this patient both at baseline and at the end of the trial. However, baseline creatine was in the upper normal range and showed a similar decrease to that observed by MRS. CSF concentrations of homovanillic acid (171 and $188 \mathrm{nmol} / \mathrm{L}$, respectively, reference range 211-871) were unchanged during the trial. Levels of CSF folates and pterines were normal (data not shown) as were concentrations of glutamate and total as well as free GABA both before and at the end of the trial (Table 1).

\section{Monitoring of EEG, MRI and MRS}

EEGs recorded at baseline were severely abnormal with frontal high amplitude slow waves (0.5-2/s) and intermittent generalized subdelta $(0.5 / \mathrm{s})$ waves. During sleep, amplitude was intermittently attenuated in irregular intervals and partly suppressed for 1-3 seconds. Multifocal sharp waves were present when awake and more frequently when asleep. EEG after 1 week of treatment showed a slightly improved background activity and the

Table 1 Relevant biochemical and MRS investigations at baseline and after four weeks glutamine supplementation

\begin{tabular}{|c|c|c|c|}
\hline Parameter & Baseline & End of trial & Reference range \\
\hline \multicolumn{4}{|l|}{ Blood } \\
\hline Ammonia ( $\mu \mathrm{mol} / \mathrm{L})$ & 66 & 76 & $12-48$ \\
\hline Glutamine $(\mu \mathrm{mol} / \mathrm{L})$ & 74 & 731 & $457-857$ \\
\hline Glutamate ( $\mu \mathrm{mol} / \mathrm{L})$ & 58 & 28 & $17-69$ \\
\hline \multicolumn{4}{|l|}{ CSF } \\
\hline Ammonia $(\mu \mathrm{mol} / \mathrm{L})$ & 71 & 75 & $12-48$ \\
\hline Glutamine ( $\mu \mathrm{mol} / \mathrm{L})$ & 121 & 201 & $333-658$ \\
\hline Glutamate $(\mu \mathrm{mol} / \mathrm{L})$ & $<2.5$ & $<2.5$ & $0-5$ \\
\hline Homovanillic acid (nmol/L) & 171 & 188 & $211-871$ \\
\hline Creatine $(\mu \mathrm{mol} / \mathrm{L})$ & 84 & 56 & $17-87$ \\
\hline Free GABA ( $\mu \mathrm{mol} / \mathrm{L})$ & 0.030 & 0.037 & $0.032-0.167$ \\
\hline Total GABA ( $\mathrm{mmol} / \mathrm{L})$ & 8.3 & 7.47 & $3.3-12.2$ \\
\hline Basal ganglia MRS & & & Reference values from age-matched comparison subjects $(n=3)$ \\
\hline NAA (IU) & 4.2 & 4.6 & $8.3-8.8$ \\
\hline Creatine + phosphocreatine (IU) & 12.0 & 10.5 & $8.4-8.6$ \\
\hline Choline (IU) & 3.6 & 2.9 & $1.7-2.0$ \\
\hline Myo-inositol (IU) & 6.7 & 6.4 & $3.0-4.0$ \\
\hline Glutamate (IU) & 4.6 & 4.9 & $7.3-10.3$ \\
\hline Glutamine (IU) & 0 & 1.4 & $3.1-6.3$ \\
\hline GABA (IU) & 3.0 & 2.6 & $2.4-3.7$ \\
\hline
\end{tabular}

Pathological values in bold; GABA: $\gamma$-aminobutyric acid; NAA: N-acetylaspartate. 
intermittent amplitude attenuation during sleep seemed to be less distinct. After 3 weeks of glutamine treatment the background activity had clearly improved with dominant $3-5 / \mathrm{s}$ activity in the awake state. After 4 weeks, intermittent amplitude attenuations completely disappeared during sleep and multifocal sharp waves were less frequent both awake and asleep (Figure 2).

The baseline MRI (performed at age $3^{9 / 12}$ years) showed changes that were not present in the previous examination at 11 months [20], including increased white matter signal intensity on T2 weighted images, prominent Virchow-Robin-spaces, reduced white matter volume with consequent thinning of the corpus callosum and secondary enlargement of CSF spaces (see Figure 3). The basal ganglia were atrophic and no contrast enhancement was present. The two following MRI exams did not show further changes (data not shown).

At baseline, MRS demonstrated undetectable glutamine, reduced $\mathrm{N}$-acetylaspartate (NAA) and glutamate and elevated creatine, choline, and myo-inositol (mI). Monitoring after two weeks revealed increased glutamine and glutamate levels and a decrease of creatine and choline with a modest increase in NAA. After four weeks, glutamine, glutamate, and NAA levels continued to increase but remained below normal. Creatine and choline levels continued to decrease but remained above normal. GABA levels decreased during the trial but remained within the normal range (Figure 4).

\section{Discussion}

Glutamine supplementation is well tolerated and partially rescues the biochemical phenotype

With this study, we provide the first report of a therapeutic trial for a patient with congenital GS deficiency. The patient is the only known living patient with this disorder [20], as the two other patients previously reported $[18,19]$ did not survive beyond the neonatal age, rendering any therapy impossible. A plausible but not proven explanation for the survival of this patient would be the assumption of a slightly higher level of GS residual activity due to another missense mutation of the GLUL gene (p.Arg324Ser in the case of the present patient [20]; p.Arg324Cys and p.Arg341Cys in the case of the neonatally deceased patients [18]). Supplementation

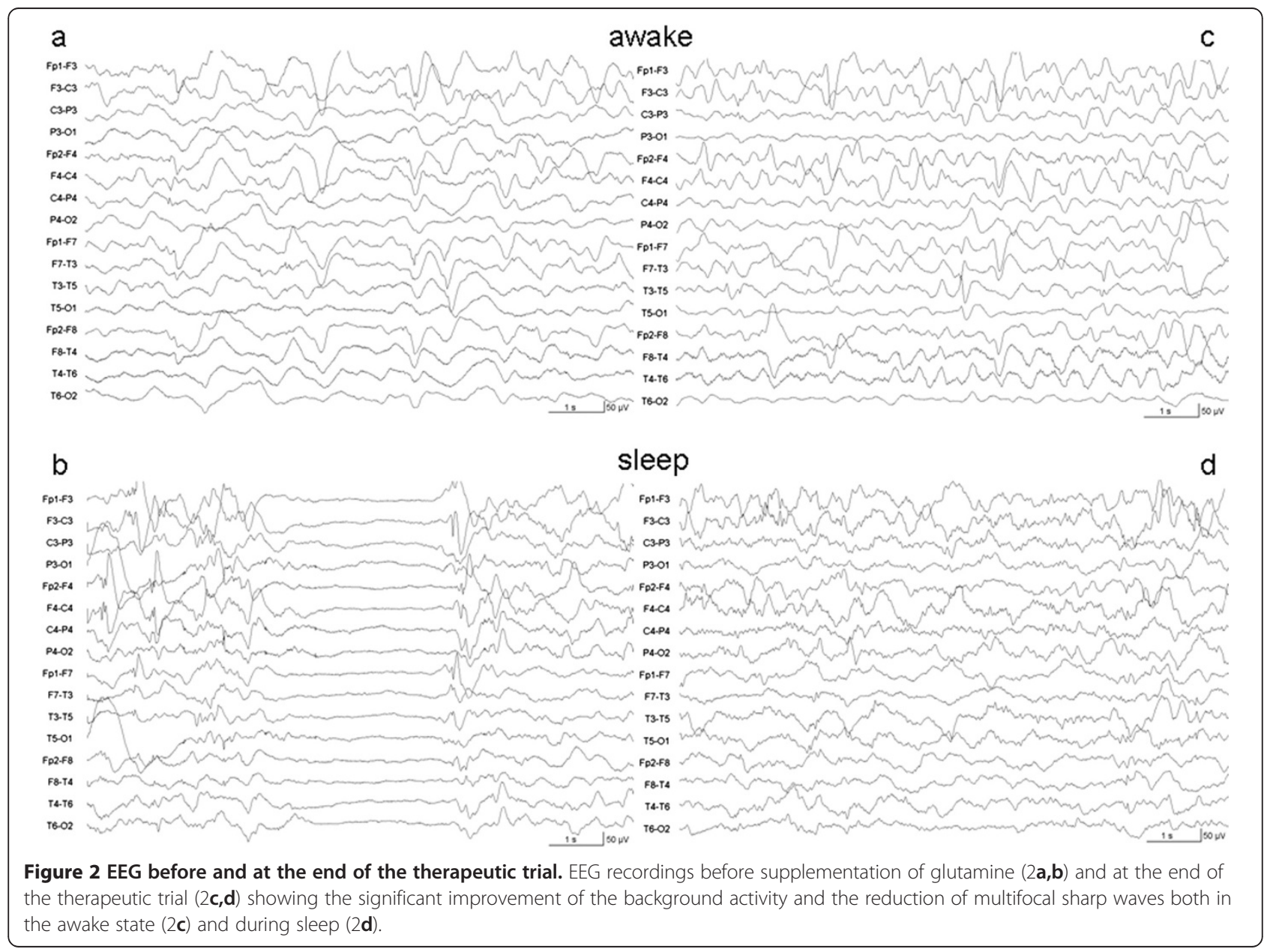




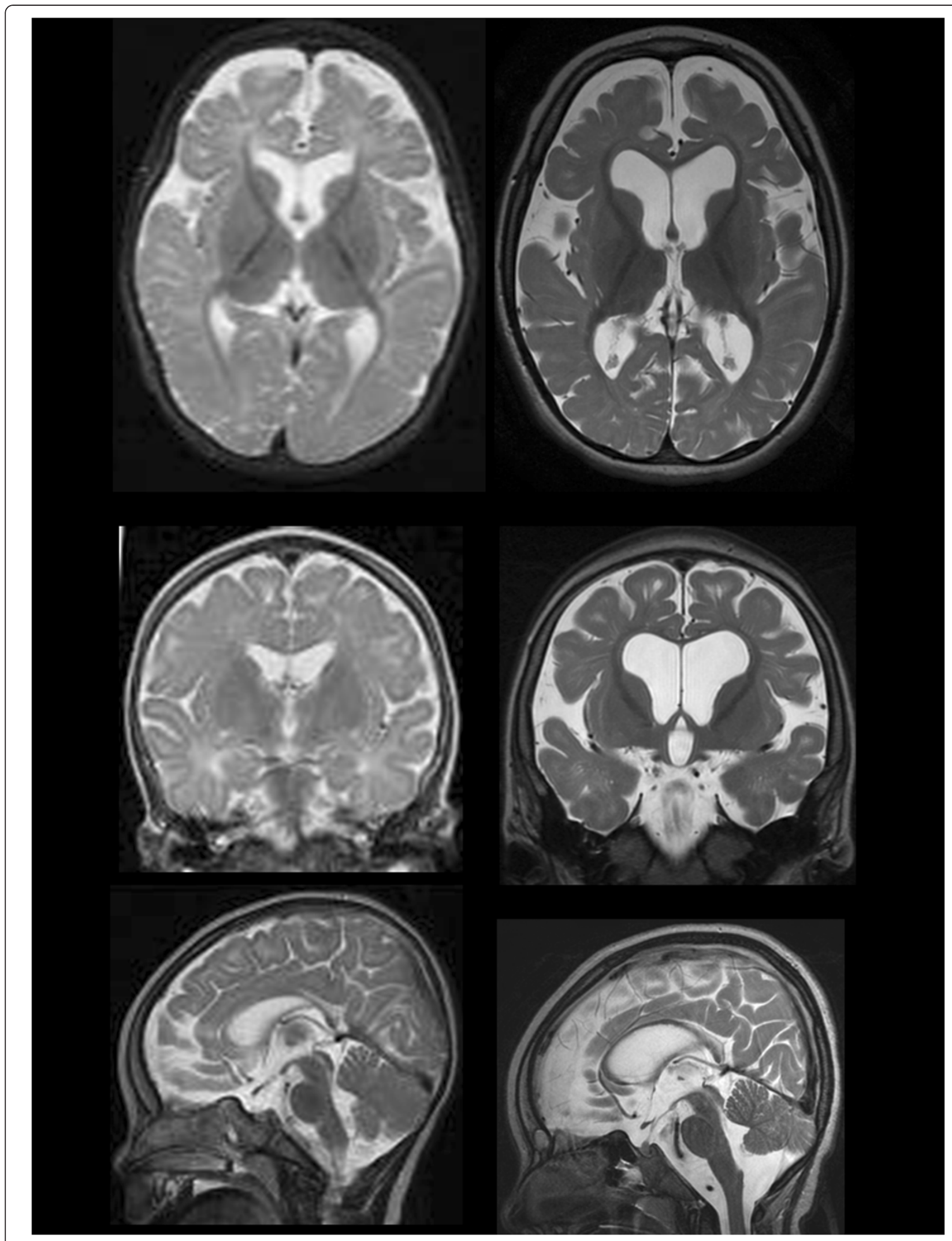

Figure 3 MRI investigations. T2 weighted images obtained at age 11 months (left column) and at the beginning of the therapeutic trial (at age $3^{9 / 12}$ years; right column) illustrating the severe brain atrophy caused by loss of cerebral white matter with consequent thinning of the corpus callosum. 


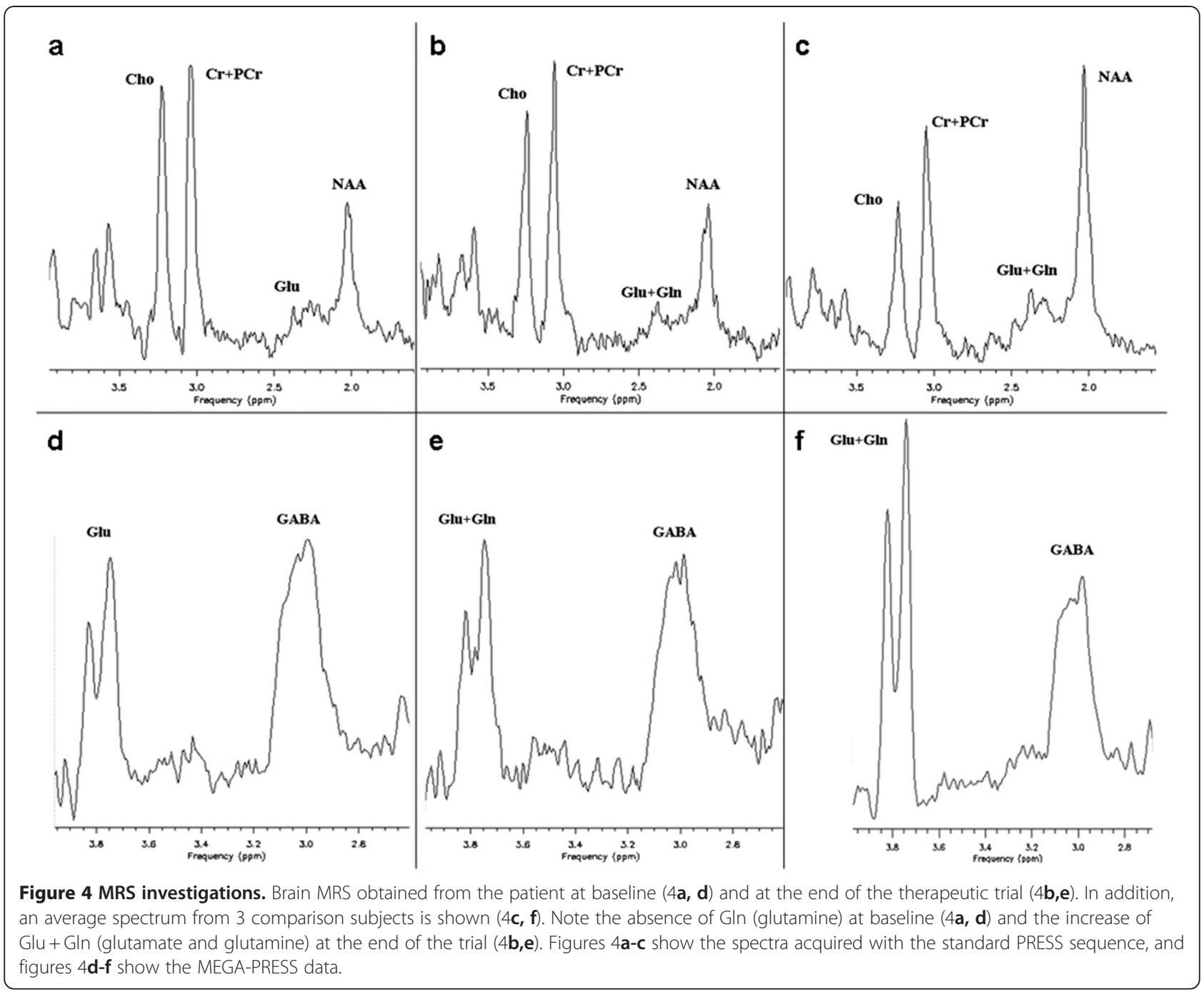

of an amino acid has already been successfully applied in other amino acid biosynthesis disorders, both in a prophylactic approach during pregnancy and in a therapeutic way postnatally $[26,27,30]$. Thus, supplementation of L-glutamine is a logical therapeutic approach, but was burdened with concerns about possible increases in ammonia and extracellular glutamate concentrations, potentially leading to neurotoxicity and increased susceptibility to seizures [31].

As the main result of this trial, the intervention was well tolerated and allowed the normalization of the peripheral biochemical phenotype of GS deficiency, as demonstrated by normal plasma glutamine levels under high-dose glutamine supplementation $(1020 \mathrm{mg} / \mathrm{kg} / \mathrm{d})$. This observation confirms earlier reports that while at normal levels of intake there is no net absorption of glutamine in the intestine of healthy individuals, additional supplementation does increase plasma glutamine concentrations $[3,21,32]$. However, in GS deficiency there is presumably some net absorption at lower levels of glutamine intake. In addition, the central biochemical phenotype could be substantially improved, as demonstrated by enhanced glutamine availability in CSF and brain tissue. Brain MRS based quantification of glutamine yielded concentrations that continuously increased from zero to measurable levels, albeit still below the findings seen in age-matched comparison subjects. MRS glutamate was also low at baseline, increasing during the trial but still remaining low relative to typical levels. Since MRS measurements of glutamate, glutamine and GABA do not provide information concerning their subcellular localisation, it is not known if the increases in glutamine and glutamate detected with MRS reflect changes in the neurotransmitter pools of these metabolites or to changes in metabolic pools. However, the lack of a further accumulation of glutamine in brain tissue is consistent with an increase in utilisation. Lack of total restoration of the biochemical phenotype in the CNS may partially be due 
to brain atrophy as shown in the basal ganglia by MRI. Atrophy and/or neurodegeneration are also supported by the low levels of NAA and the elevated levels of creatine and choline demonstrated by MRS and CSF measurements.

In normal subjects, the glutamine transporter SN1 (SLC38A3) at the astroglial membranes maintains glutamine concentrations in the extracellular fluid around $0.4 \mathrm{mM}$ by bidirectional glutamine transport [33,34]. With a dysfunctional GS the astroglial cells no longer produce glutamine and their contribution to the extracellular glutamine homeostasis is abolished. With glutamine supplementation, glutamine will cross the blood-brain barrier and increase the levels of glutamine in the perisynaptic extracellular compartments [35]. Many of the neuronal glutamine transporters - including the unidirectional system A transporters SAT1 (SLC38A1) and SAT2 (SLC38A2) shown to be fundamental for neurotransmitter generation $[17,36,37]$ - have $\mathrm{Km}$ values in the order of 0.2-2.3 $\mathrm{mM}$ for glutamine [38,39]. These transporters will be stimulated by the increased supply of glutamine, enabling the neurons to accumulate glutamine continuously and facilitating the catabolism of glutamine to sustain synthesis of the neurotransmitters glutamate and GABA [36]. Thus, lack of further buildup of glutamine in brain tissue and in CSF is consistent with its increased utilization. Furthermore, our data suggest that glutamine supplementation counteracts the imbalance in glutamatergic and GABAergic drive described in some forms of epilepsy [40] and we speculate that this might form the basis of the improvement in the background EEG activity, reflecting the clinical amelioration of the encephalopathy. Thus, our data show that glutamine supplementation succeeded in increasing the supply of glutamine throughout the body, possibly stimulating cellular metabolism and sustaining normal function.

\section{Glutamine supplementation does not aggravate hyperammonemia}

As demonstrated in this study, levels of plasma and CSF ammonia remained stable even when glutamine supplementation was increased to the maximum of $1020 \mathrm{mg} / \mathrm{kg} / \mathrm{d}$. The slightly higher plasma ammonia concentrations at the end of the trial are likely attributed to the infection, as concomitant CSF ammonia levels remained unchanged in comparison to baseline levels (Table 1). Our results correspond well to data gained from genetic disruption of GS in mice which show a modest increase (1.6 fold) in cortical ammonia levels [41]. However, in addition, we show that a therapeutic intervention with glutamine supplementation does not exacerbate the levels of plasma and CSF ammonia in a human. Unfortunately, there was no close monitoring of ammonia (or amino acid profiles) after the discharge of the patient from the hospital when he developed irritability, so no conclusions can be drawn with regard to the cause of this irritability.

\section{Glutamine is critically needed during pregnancy, in the neonatal and early childhood periods}

The severe changes in cerebral white matter at the beginning of the therapeutic trial (Figure 3) demonstrate that the brain of the patient has probably deteriorated over the years due to glutamine deficiency and lack of its metabolic products, and due to severe epileptic encephalopathy. This observed neurodegeneration is consistent with experimental findings supporting the role of GS for Schwann cell differentiation [42]. During pregnancy, there is a great need for glutamine for normal ontogeny and brain development $[43,44]$ and there is GS-dependent de novo synthesis of glutamine in the placenta [45]. As the glutamine transporters on the placenta are also upregulated to transport glutamine actively from the maternal circulation to the fetus the demand may be partially met by increased extraction of glutamine from the maternal circulation [46]. However, this supply is abolished after birth, while the demand for glutamine - e.g. for glutamate and GABA formation and myelination - continues to increase due to synaptogenesis and establishment of functional neuronal networks [47].

Substantial clinical improvement in the patient's condition was therefore unlikely. However, the improvement in alertness of the patient, although difficult to quantify for external evaluation, can be considered as encouraging with respect to an earlier start of treatment in future patients. Likewise, EEG recordings were much improved both in the awake and sleeping state, suggesting that external glutamine can cross the blood brain barrier and possibly influence neuronal activity. Of note, enteral glutamine supplementation was sufficient to establish and maintain normal plasma glutamine levels. As an alternative if enteral use is not feasible, parenteral application was also possible in this patient but was considered as a second choice given the higher invasiveness.

\section{Conclusions}

In summary, this is the first report of a therapeutic intervention in a patient with an inherited defect of GS, demonstrating the feasibility of correcting systemic glutamine deficiency in this disorder without worsening pre-existing hyperammonemia or provoking toxic CSF glutamate levels. For future patients, glutamine supplementation should begin as early as possible in order to elucidate to what extent earlier intervention can prevent the devastating natural course of chronic encephalopathy in GS deficiency. In fact, since glutamine is a functionally essential amino acid also in healthy persons, adequate maternal production and supply of glutamine 
to the fetal circulation may be a limiting factor in particular in the presence of GS deficiency in the placenta. Thus, glutamine supplementation may have beneficial outcomes during pregnancy for a child with GS deficiency and should be considered. Since newborn screening programs will probably not adopt GS deficiency as a target disease based on its extremely low incidence and on the instability of glutamine in dried blood samples, a high awareness towards low glutamine levels found in selective screening is needed. Moreover, additional research is warranted to make headway towards ameliorating the effects of this devastating condition as well as to improve outcomes for this rare genetic disease.

\section{Competing interests}

The authors declare that they have no competing interests.

\section{Authors' contributions}

All authors of this work have contributed to the planning and performing of the study as well as to writing and revising of this paper. All authors read and approved the final manuscript.

\section{Acknowledgements}

The authors are truly obliged to the family of this patient who willingly cooperated in this therapeutic trial. We acknowledge the kind support of Cornelis Jacobs, VU medisch centrum Amsterdam, for studying concentrations of total and free GABA in CSF and the help provided by Richard Edden, the Johns Hopkins University, Baltimore, for the MEGA-PRESS sequence. This study has been supported by a generous grant from Qatar Foundation, which had, however, no influence on study design, data collection, analysis and interpretation, and writing of the manuscript.

\section{Author details}

'Division of Metabolism and Children's Research Center, University Children's Hospital Zurich, 8032 Zurich, Switzerland. ${ }^{2}$ Section of Clinical and Metabolic Genetics, Doha, Qatar. ${ }^{3}$ Section of Pediatric Neurology, Department of Pediatrics, Hamad Medical Corporation, Doha, Qatar. ${ }^{4}$ Division of Neuropediatrics, University Children's Hospital Zurich, Zurich, Switzerland. ${ }^{5}$ Division of Radiology, University Children's Hospital Zurich, Zurich, Switzerland. ${ }^{6}$ Center for Magnetic Resonance Research, University Children's Hospital Zurich, Zurich, Switzerland. ${ }^{7} T h e$ Biotechnology Centre and The Centre for Molecular Biology and Neuroscience, University of Oslo, Oslo, Norway. ${ }^{8}$ Department of Pediatrics and Genetic Medicine, Weil-Cornell Medical College, New York, USA. ${ }^{9}$ Department of Pediatrics and Genetic Medicine, Weil-Cornell Medical College, Doha, Qatar.

Received: 27 March 2012 Accepted: 6 July 2012

Published: 25 July 2012

\section{References}

1. Häussinger D: Hepatic glutamine transport and metabolism. Adv Enzymo Relat Areas Mol Biol 1998, 72:43-86.

2. Kumada Y, Benson DR, Hillemann D, Hosted TJ, Rochefort DA, Thompson CJ, Wohlleben W, Tateno Y: Evolution of the glutamine synthetase gene, one of the oldest existing and functioning genes. Proc Natl Acad Sci USA 1993, 90:3009-3013.

3. Watford M: Glutamine metabolism and function in relation to proline synthesis and the safety of glutamine and proline supplementation. J Nutr 2008, 138:2003S-2007S.

4. Labow BI, Souba WW, Abcouwer SF: Mechanisms governing the expression of the enzymes of glutamine metabolism--glutaminase and glutamine synthetase. J Nutr 2001, 131:2467S-2474S. discussion 2486S-2467S.

5. Martinez-Hernandez A, Bell KP, Norenberg MD: Glutamine synthetase: glial localization in brain. Science 1977, 195:1356-1358.
6. Suarez I, Bodega G, Fernandez B: Glutamine synthetase in brain: effect of ammonia. Neurochem Int 2002, 41:123-142.

7. Häussinger $\mathrm{D}, \mathrm{Graf} \mathrm{D}$, Weiergraber $\mathrm{OH}$ : Glutamine and cell signaling in liver. J Nutr 2001, 131:2509S-2514S. discussion 2523S-2504S.

8. Häussinger D: Nitrogen metabolism in liver: structural and functional organization and physiological relevance. Biochem J 1990, 267:281-290.

9. Vermeulen T, Görg B, Vogl T, Wolf M, Varga G, Toutain A, Paul R, Schliess F, Häussinger D, Häberle J: Glutamine synthetase is essential for proliferation of fetal skin fibroblasts. Arch Biochem Biophys 2008, 478:96-102.

10. He Y, Hakvoort TB, Vermeulen JL, Lamers WH, Van Roon MA: Glutamine synthetase is essential in early mouse embryogenesis. Dev Dyn 2007, 236:1865-1875.

11. Caggese C, Caizzi R, Barsanti P, Bozzetti MP: Mutations in the glutamine synthetase I (gsl) gene produce embryo-lethal female sterility in Drosophila melanogaster. Dev Genet 1992, 13:359-366.

12. Häussinger D, Sies R: In Glutamate Metabolism in Mammalian Tissues. Edited by Häussinger D, Sies R. Berlin: Springer; 1984:3-15.

13. Solbu TT, Boulland JL, Zahid W, Lyamouri Bredahl MK, Amiry-Moghaddam M, Storm-Mathisen J, Roberg BA, Chaudhry FA: Induction and targeting of the glutamine transporter SN1 to the basolateral membranes of cortical kidney tubule cells during chronic metabolic acidosis suggest a role in pH regulation. J Am Soc Nephrol 2005, 16:869-877.

14. Gammelsaeter R, Jenstad M, Bredahl MK, Gundersen V, Chaudhry FA: Complementary expression of SN1 and SAT2 in the islets of Langerhans suggests concerted action of glutamine transport in the regulation of insulin secretion. Biochem Biophys Res Commun 2009, 381:378-382.

15. Chaudhry FA, Reimer RJ, Edwards RH: The glutamine commute: take the $\mathrm{N}$ line and transfer to the A. J Cell Biol 2002, 157:349-355.

16. Chaudhry FA, Boulland JL, Jenstad M, Bredahl MK, Edwards RH: Pharmacology of neurotransmitter transport into secretory vesicles. Handb Exp Pharmacol 2008:77-106.

17. Albrecht J, Sidoryk-Wegrzynowicz M, Zielinska M, Aschner M: Roles of glutamine in neurotransmission. Neuron Glia Biol 2010, 6:263-276.

18. Häberle J, Görg B, Rutsch F, Schmidt E, Toutain A, Benoist JF, Gelot A, Suc AL, Höhne W, Schliess F, et al: Congenital glutamine deficiency with glutamine synthetase mutations. N Engl J Med 2005, 353:1926-1933.

19. Häberle J, Görg B, Toutain A, Rutsch F, Benoist JF, Gelot A, Suc AL, Koch HG, Schliess F, Häussinger D: Inborn error of amino acid synthesis: human glutamine synthetase deficiency. J Inherit Metab Dis 2006, 29:352-358.

20. Häberle J, Shahbeck N, Ibrahim K, Hoffmann GF, Ben-Omran T: Natural course of glutamine synthetase deficiency in a 3 year old patient. Mol Genet Metab 2011, 103:89-91.

21. Garlick PJ: Assessment of the safety of glutamine and other amino acids. J Nutr 2001, 131:2556S-2561S.

22. Gleeson M: Dosing and efficacy of glutamine supplementation in human exercise and sport training. J Nutr 2008, 138:2045S-2049S.

23. Ziegler TR, Benfell K, Smith RJ, Young LS, Brown E, Ferrari-Baliviera E, Lowe DK, Wilmore DW: Safety and metabolic effects of L-glutamine administration in humans. JPEN J Parenter Enteral Nutr 1990, 14:137S-146S.

24. Boza JJ, Maire J, Bovetto L, Ballevre O: Plasma glutamine response to enteral administration of glutamine in human volunteers (free glutamine versus protein-bound glutamine). Nutrition 2000, 16:1037-1042.

25. Albrecht J, Norenberg MD: Glutamine: a Trojan horse in ammonia neurotoxicity. Hepatology 2006, 44:788-794.

26. de Koning TJ: Treatment with amino acids in serine deficiency disorders. $J$ Inherit Metab Dis 2006, 29:347-351.

27. de Koning TJ, Klomp LW, van Oppen AC, Beemer FA, Dorland L, van den Berg I, Berger R: Prenatal and early postnatal treatment in 3-phosphoglycerate-dehydrogenase deficiency. Lancet 2004, 364:2221-2222.

28. Mescher M, Merkle H, Kirsch J, Garwood M, Gruetter R: Simultaneous in vivo spectral editing and water suppression. NMR Biomed 1998, 11:266-272

29. Provencher SW: Estimation of metabolite concentrations from localized in vivo proton NMR spectra. Magn Reson Med 1993, 30:672-679.

30. Martinelli D, Häberle J, Rubio V, Giunta C, Hausser I, Carrozzo R, Gougeard N, Marco-Marin C, Goffredo BM, Meschini MC, et al: Understanding pyrroline5-carboxylate synthetase deficiency: clinical, molecular, functional, and expression studies, structure-based analysis, and novel therapy with 
arginine. J Inherit Metab Dis 2012, doi:10.1007/s10545-011-9411-8. 2011 Dec 15. [Epub ahead of print].

31. Olney JW, Collins RC, Sloviter RS: Excitotoxic mechanisms of epileptic brain damage. Adv Neurol 1986, 44:857-877.

32. Lacey JM, Crouch JB, Benfell K, Ringer SA, Wilmore CK, Maguire D, Wilmore DW: The effects of glutamine-supplemented parenteral nutrition in premature infants. JPEN J Parenter Enteral Nutr 1996, 20:74-80.

33. Chaudhry FA, Reimer RJ, Krizaj D, Barber D, Storm-Mathisen J, Copenhagen $\mathrm{DR}$, Edwards RH: Molecular analysis of system $\mathrm{N}$ suggests novel physiological roles in nitrogen metabolism and synaptic transmission. Cell 1999, 99:769-780.

34. Chaudhry FA, Krizaj D, Larsson P, Reimer RJ, Wreden C, Storm-Mathisen J, Copenhagen D, Kavanaugh M, Edwards RH: Coupled and uncoupled proton movement by amino acid transport system N. EMBO J 2001, 20:7041-7051.

35. Xiang J, Ennis SR, Abdelkarim GE, Fujisawa M, Kawai N, Keep RF: Glutamine transport at the blood-brain and blood-cerebrospinal fluid barriers. Neurochem Int 2003, 43:279-288.

36. Jenstad M, Quazi AZ, Zilberter $M$, Haglerod C, Berghuis P, Saddique N, Goiny M, Buntup D, Davanger S, Haug FMS, et al: System A transporter SAT2 mediates replenishment of dendritic glutamate pools controlling retrograde signaling by glutamate. Cereb Cortex 2009, 19:1092-1106.

37. Solbu TT, Bjorkmo M, Berghuis P, Harkany T, Chaudhry FA: SAT1, A Glutamine Transporter, is Preferentially Expressed in GABAergic Neurons. Front Neuroanat 2010, 4:1.

38. Chaudhry FA, Schmitz D, Reimer RJ, Larsson P, Gray AT, Nicoll R, Kavanaugh M, Edwards RH: Glutamine uptake by neurons: interaction of protons with system a transporters. J Neurosci 2002, 22:62-72.

39. Yao D, Mackenzie B, Ming H, Varoqui $H$, Zhu H, Hediger MA, Erickson JD: A novel system $\mathrm{A}$ isoform mediating $\mathrm{Na}+$ /neutral amino acid cotransport. J Biol Chem 2000, 275:22790-22797.

40. Eid T, Williamson A, Lee TS, Petroff OA, de Lanerolle NC: Glutamate and astrocytes-key players in human mesial temporal lobe epilepsy? Epilepsia 2008, 49(Suppl 2):42-52.

41. He Y, Hakvoort TB, Vermeulen JL, Labruyere WT, De Waart DR, Van Der Hel WS, Ruijter JM, Uylings HB, Lamers WH: Glutamine synthetase deficiency in murine astrocytes results in neonatal death. Glia 2010, 58:741-754.

42. Saitoh F, Araki T: Proteasomal degradation of glutamine synthetase regulates schwann cell differentiation. J Neurosci 2010, 30:1204-1212.

43. Battaglia FC: Glutamine and glutamate exchange between the fetal liver and the placenta. J Nutr 2000, 130:974S-977S

44. Boulland JL, Rafiki A, Levy LM, Storm-Mathisen J, Chaudhry FA: Highly differential expression of SN1, a bidirectional glutamine transporter, in astroglia and endothelium in the developing rat brain. Glia 2003, 41:260-275.

45. Manso Filho HC, Costa HE, Wu G, McKeever KH, Watford M: Equine placenta expresses glutamine synthetase. Vet Res Commun 2009, 33:175-182.

46. Desforges M, Mynett KJ, Jones RL, Greenwood SL, Westwood M, Sibley CP, Glazier JD: The SNAT4 isoform of the system A amino acid transporter is functional in human placental microvillous plasma membrane. J Physiol 2009, 587:61-72.

47. Boulland JL, Qureshi T, Seal RP, Rafiki A, Gundersen V, Bergersen LH, Fremeau RT Jr, Edwards RH, Storm-Mathisen J, Chaudhry FA: Expression of the vesicular glutamate transporters during development indicates the widespread corelease of multiple neurotransmitters. J Comp Neurol 2004, 480:264-280.

doi:10.1186/1750-1172-7-48

Cite this article as: Häberle et al: Glutamine supplementation in a child with inherited GS deficiency improves the clinical status and partially corrects the peripheral and central amino acid imbalance. Orphanet Journal of Rare Diseases 2012 7:48.

\section{Submit your next manuscript to BioMed Central and take full advantage of:}

- Convenient online submission

- Thorough peer review

- No space constraints or color figure charges

- Immediate publication on acceptance

- Inclusion in PubMed, CAS, Scopus and Google Scholar

- Research which is freely available for redistribution

Submit your manuscript at www.biomedcentral.com/submit
() Biomed Central 